\title{
Homelessness and Incarceration
}

Erin Dej and Dale Spencer

\section{SPECIAL ISSUE EDITORS}

Erin Dej, PhD

Assistant Professor, Criminology, Wilfrid Laurier University

Dale Spencer, PhD

Associate Professor, Law and Legal Studies, Carleton University

\section{FOCUS OF THE SPECIAL ISSUE}

There is a considerable writing on incarceration and homelessness, yet there is very little contributions on the relationship between the two, especially from current and formerly incarcerated and homeless persons. In this special issue, we invite contributions that explore the connection between experiences of incarceration and homelessness. The issue takes a broad understanding of what constitutes homelessness (unsheltered, emergency sheltered, unstably housed, at risk of homelessness) and what constitutes incarceration (recognizing how various systems and institutions are implicated in widening the carceral net). Submissions can address, but are not restricted, to the following topics below.

\section{The homelessness-incarceration pipeline}

- Incarceration causing homelessness

- Homelessness causing incarceration

- The criminalization of homelessness

\section{Experiences of homelessness and incarceration}

- The lived experiences of being without a home

- Incarceration as a form of homelessness

\section{Structural and systems drivers of homelessness and incarceration}

- Discharge from corrections into homelessness

- Those without a fixed address denied bail/held in remand

- Unfair/unrealistic bail conditions for those without a home to maintain

- Barriers to accessing services geared towards people experiencing homelessness due to criminal record 


\section{Intersectional experiences of homelessness and incarceration}

- Homelessness and incarceration as tools of settler colonialism

- Newcomers experiences of incarceration (including immigration detention centres)

- Women-identifying people's experiences of homelessness and incarceration

- Youth experiences with the criminal justice system and homelessness (including how discrimination facing LGBTQ2S+ youth impacts homelessness and/or incarceration)

\section{PAPER FORMATS}

Prisoners and former prisoners, along with other co-authors (where applicable) are encouraged to submit papers, collaborative essays, discussions transcribed from tape, book reviews, and photo or graphic essays. All contributions must follow the journal's submission guidelines (http://www.jpp.org/submissions.html).

\section{IMPORTANT DATES}

Notice of intent to submit paper with abstract:

Invitation from issue editors to submit paper:

Submissions by authors:

Editorial decision and reviewer comments to authors:

Revised manuscripts:

Publication date:
August 1, 2021

September 1, 2021

February 1, 2022

April 1, 2022

July 1, 2022

2023

\section{SUBMISSIONS}

Via email to edej@wlu.ca or by mail to the address below:

Erin Dej, PhD

Department of Criminology

Wilfrid Laurier University

171 Colborne St.

Brantford, ON

N3T 6 C9 